\title{
The old order changeth yielding place to new
}

\section{Søren Holm, John Harris}

\section{Editors-in-Chief Søren Holm and John Harris announce exciting changes for the journal}

$\mathrm{S}$ tarting with this issue, the Journal of Medical Ethics has a new editorial team. We inherit one of the bestwe believe the best-journal concerned with medical ethics and bioethics in the world. Certainly it is the journal with the highest impact factor in bioethics, applied philosophy, and medical ethics. For this we have to thank not only Julian Savulescu from whom we take over but also the two previous editors, Raanan Gillon and Alistair Campbell.

Søren Holm and John Harris are the new Editors-in-Chief and the editorial team welcomes several new members: Richard Ashcroft and Nikola BillerAndorno as Deputy Editors, Derek Morgan as Legal Editor, John McMillan as Book Reviews Editor, and Mike Parker, who will be responsible for the links between the $B M J$ and $J M E$. Ruth Coster will continue running the editorial office. Further details of roles and responsibilities, and the new postal address for the editorial office, can be found on the JME website (http:// www.jmedethics.com).

Our aim and firm purpose is to make this journal the best in the world: best for its readers, best for contributors, most useful to health professionals, policy makers, students, and anyone interested in the ethical and legal dilemmas presented by medical practice and the life sciences. We welcome suggestions as to how to achieve this but to start with we have some exciting plans which will begin to take effect very soon.

Perhaps most important is the decision to go monthly: from 2005 the journal will appear every month. This will make us the first medical ethics or bioethics journal to do so. Monthly publication will have a number of important consequences. Firstly, it will enable $J M E$ to be responsive to breaking news. We hope that readers will always be able to find informative and in depth analysis and comment on any major scientific or clinical event or news story breaking in time for inclusion in the next issue. Secondly it will enable us to get contributors' articles into press with greater rapidity. We will aim for publication within six months of acceptance and we intend to give early decisions on all submissions. This, we hope, will be good for contributors but also for readers, as papers will be timely and relevant to contemporary concerns.
Web based publication of a number of our features-current controversies, editor's choice, reviews, and so on-will both provide open access and prompt publication.

The journal will continue to be global both in its concerns and in its approach; its ethos will remain inclusive and no specific approach to medical ethics will be privileged. We want $J M E$ to continue to attract new contributions from young academics and health professionals but also from the leading figures in the field. Developing world concerns and international issues will increasingly be on the agenda. The journal will therefore continue its policy of open access to all content for scholars in the developing world, and we very much welcome contributions from the developing world. In the next couple of months we will issue a number of calls for papers on current issues, so please watch this space.

\section{HOW TO CONTACT US}

If you have any suggestions concerning how to make JME better, feel free to email the editors: holms@cardiff.ac. uk or john.m.harris@man.ac.uk

J Med Ethics 2004;30:331.

doi: 10.1136/jme.2004.009720

...............

Authors' affiliations

S Holm, Cardiff Law School, University of Cardiff, Cardiff, UK

J M Harris, The Centre for Social Ethics and Policy, University of Manchester, Manchester, UK

Correspondence to: Professor J M Harris, The Centre for Social Ethics and Policy, School of Law, University of Manchester, Williamson Building, Oxford Road, Manchester M13 OJH, UK; john.m.harris@man.ac.uk 